\section{AL-AZHAR}

Assiut Dental Journal
The Official Publication of The

Faculty of Dental medicine.

Al-Azhar Assiut Uniuersity.

AADJ, Vol. 3, No. 1, April (2020) - PP. 7:18

ISSn 2682-2822

\title{
Effect of Cavity Design and Cusp Inclination on Fracture Resistance of Indirect Overlay Restorations In Maxillary First Pemolars: An In Vitro Study
}

\author{
Roqaia M. Alassar ${ }^{* 1}$, Amira M.Samy, ${ }^{2}$ and Rania A. Amin ${ }^{1}$
}

Codex : 02/2020/04

Aadj@azhar.edu.eg

\section{KEYWORDS}

Cavity Design, Cusp Inclination, Fracture Resistance, Overlay, Restorations, Premolars.
1. Department of Crowns and Bridges, Faculty of Dental Medicine )Girls), Cairo, AlAzhar University, Egypt

2. Department of Conservative Dentistry, Faculty of Oral and Dental Medicine, Modern University for Technology \& Information, Cairo, Egypt

* Corresponding Author e-mail: roqaiaalassar.26@azhar.edu.eg

\begin{abstract}
Aim: to evaluate the effect of cavity design and cusp inclination on fracture resistance of indirect overlay restorations in maxillary $1^{\text {st }}$ premolars. Subjects and Methods: Hundred extracted human maxillary $1^{\text {st }}$ premolars were selected and divided into ten groups; Gr1: control group (CG), Gr2: shoulder design with normal cusp inclination, Gr3 \& Gr4: shoulder design with $33^{\circ} \& 22^{\circ}$ cusp inclinations (respectively, Gr5: butt joint design with normal cusp inclination, Gr6 \& Gr7: butt joint design with $33^{\circ} \& 22^{\circ}$ cusp inclinations respectively, Gr8: Anatomical design with normal cusp inclination, Gr9 \& Gr10: Anatomical design with $33^{\circ} \& 22^{\circ}$ cusp inclinations respectively. All restorations were fabricated indirectly and cemented by RelyX Ultimate adhesive resin cement. Samples were stored for $24 \mathrm{hrs}$ in distilled water at $37^{\circ} \mathrm{C}$ and then thermocycled for 5000 cycles. Universal testing machine was used to measure fracture loads. Samples were examined for determination of failure mode using a magnifying lens. Results: ANOVA test revealed that the difference between groups was statistically significant $(\mathrm{p}=0.00)$. Tukey's post hoc test revealed no significant difference between $\mathrm{Sh} / 33^{\circ} \mathrm{CI}, \mathrm{Sh} / 22^{\circ} \mathrm{CI}, \mathrm{B} / 33^{\circ} \mathrm{CI}, \mathrm{B} / 22^{\circ} \mathrm{CI}, \mathrm{A} / \mathrm{NCI}$ and $\mathrm{A} / 33^{\circ} \mathrm{CI}$. Conclusions: The teeth restored with cusp shoulder designs exhibited the highest percentages of restorable fractures (70-90\%). Anatomical design presents the highest fracture resistance. However, 70-100\% catastrophic failure is suspected. Fracture resistance increases significantly by decreasing cusp inclination of overlay restorations.
\end{abstract}

\section{INTRODUCTION}

In retrospective studies and reviewed articles, the incidence rate of maxillary premolar fractures were reported as quite common, particularly in teeth with large intracoronal restorations. ${ }^{(1-4)}$ It was reported that buccal cusps fractured more frequently than palatal cusps in maxillary premolars and most of the teeth with cusp fractures were associated with restored teeth and most of them were vital. ${ }^{(2,3)}$ The reduced amount of dentin supporting the cusps of a restored tooth is thought to be the direct cause of cusp fracture, ${ }^{(5)}$ while the indirect cause is suggested to be related to degree of cusp inclination. ${ }^{(6)}$ In group 
function occlusion, as a result of high and steep cusps, maxillary premolars are exposed to repeated oblique occlusal forces that are translated into high lateral forces. ${ }^{(6)}$ This situation is the worst for maxillary premolars as the risk of tooth fracture and restoration debonding is much higher. ${ }^{(7-11)}$

Therefore, for restoring vital maxillary premolars with limited remaining coronal dentin, crown restoration is not considered as a conservative line of treatment. Instead, overlay restoration with modified occlusal scheme is suggested to protect the supporting units and the restoration from overload. ${ }^{(12)}$ It is highly recommended minimizing the lateral forces to reduce the risk of fracture. ${ }^{(13)}$

Overlay (or partial crown) is an indirect esthetic restoration for vital posterior teeth characterized by MOD inlay portion extended to cover the whole occlusal surface to protect all cusps. ${ }^{(14)}$ The construction method depends on the selected restorative material. Nano-ceramic composite can be used indirectly for overlay construction according to manufacturer recommendation.

Indirect esthetic restoration is a clinical decision daily practiced by many dentists. There are specific guidelines for this decision. When a restoration is too difficult to make directly as in cases of cusp fracture and large defective size, or when optimal form and esthetics are required, an indirect restoration can be more successful. In addition, for predictable full mouth rehabilitations, a preoperative diagnostic wax-up is of a great importance for reconstructions by indirect techniques. ${ }^{(15)}$

In general, indirect techniques have many advantages, especially when ceramic materials of high fracture strength are used. With improvements in dental adhesive systems, the indirect restorations are expected to have better longevity than direct restorations. Using composite materials indirectly leads to controlled polymerization shrinkage and less microleakage, as well. ${ }^{(15)}$
To save clinical time, ensure excellent marginal fit, ideal proximal contacts, optimal occlusal relationship, reduced polymerization, high fracture resistance, high wear resistance, optimal aesthetic and better color stability, some clinicians prefer construction of composite restoration indirectly rather than inside patient's mouth. ${ }^{(16)}$ After cavity preparation, the indirect technique includes bite registration, impression taking, pouring into cast and mounting on an articulator, restoration building up, light curing, finishing and polishing. Finally, adhesive cementation and rechecking occlusion are a must.

An in-vitro study compared the fracture strength of teeth restored with bonded ceramic overlays to sound teeth and reported that the fracture strength of teeth restored with ceramic overlays was similar to that of intact teeth. ${ }^{(17)}$ In 2014, the effect of different cusp coverage patterns on fracture resistance of maxillary premolar teeth in MOD composite restorations was studied. It was concluded that coverage of both buccal and lingual cusps in large MOD composite restorations of maxillary premolars significantly increases the fracture resistance of teeth compared to the coverage of one cusp or no cusp coverage. ${ }^{(18)}$ In addition, the fracture resistance and failure pattern of inlay, onlay and overlay cavity designs restored with monolithic zirconia were evaluated. Overlays had shown a significant increase in the fracture resistance than the sound teeth. ${ }^{(19)}$ Moreover, in 2018, the relation between cracked teeth with different cusp inclination and maximum resistance strength was investigated and found that when cusp inclination decreases to a certain angle, resistance strength is increased and the possibility of cracking will decrease. (20)

Therefore, the aim of this in vitro study was to evaluate the effect of cavity designs and cusp inclinations on fracture resistance of maxillary $1^{\text {st }}$ premolars restored with overlay restorations. The null hypothesis tested was that cavity design and cusp inclination have no influence on fracture resistance of maxillary $1^{\text {st }}$ premolars restored with overlay restorations. 


\section{MATERIALS AND METHODS}

To conduct the present study, hundred human maxillary $1^{\text {st }}$ premolars freshly extracted for orthodontic reasons, approximately similar in size and free of any attrition signs were selected in accordance with guidelines from research ethics committee approval of Faculty of Dental Medicine for Girls, Al Azhar University. The teeth were rinsed thoroughly under running water, cleaned and stored in $0.1 \%$ thymol sol. Roots were imbedded in acrylic resin blocks (Acrostone, Egypt) with a stimulated periodontal ligament created by using light body rubber base impression material (Zetalabor; Zhermack SPA, Italy) to allow adequate stabilization of the teeth during testing procedures.

\section{Samples grouping;}

The samples were randomly divided into ten groups ( $n=10)$ according to cavity design and degree of buccal cusp inclination. Grouping of samples was illustrated in figure 1. Group 1 was positive control group (intact teeth).

\section{Teeth preparation;}

Ninety teeth were divided into 3 groups to receive standardized MOD inlay preparations, in accordance with general principles for esthetic inlay restorations. ${ }^{(21)}$ For overlay preparations, buccal and palatal cusps were reduced with three different designs; cusp shoulder, butt joint, and anatomical designs. (Fig 1)

\section{Cavity preparation guidelines:}

Centroid milling machine (CNC, USA) with two diamond stones selected from the Inlay/ Onlay preparation Kit (Zhengzhou Smile Dent Equip, China) was used to perform standardized preparations. The occlusal cavity occupied $3 \mathrm{~mm}$ bucco-lingually and $5 \mathrm{~mm}$ mesio-distally. The depth was adjusted at $2 \mathrm{~mm}$ measured from central groove. Proximal cavities were extended with flared buccal and lingual walls (4mm buccolingually). The proximal box was $4 \mathrm{~mm}$ long and $1.5 \mathrm{~mm}$ deep. Occlusal divergence angle was set at $10^{\circ}-12^{\circ}$. Cavosurface margins were finished in butt joints with no bevels. Internal line and point angles were rounded. Buccal and palatal cusps were $2 \mathrm{~mm}$ occlusally reduced with $1 \mathrm{~mm}$ cusp shoulder for $\mathrm{Gr}$ 2,3,4 and with butt joint for $\mathrm{Gr} 5,6,7$, while in $\mathrm{Gr}$ 8,9 and 10 , cusps were $2 \mathrm{~mm}$ anatomically reduced following the contour of buccal and palatal cusp inclinations. Prepared dentin was sealed with an adhesive system (Single bond, 3M, USA) to prevent contamination. (Figs 2)

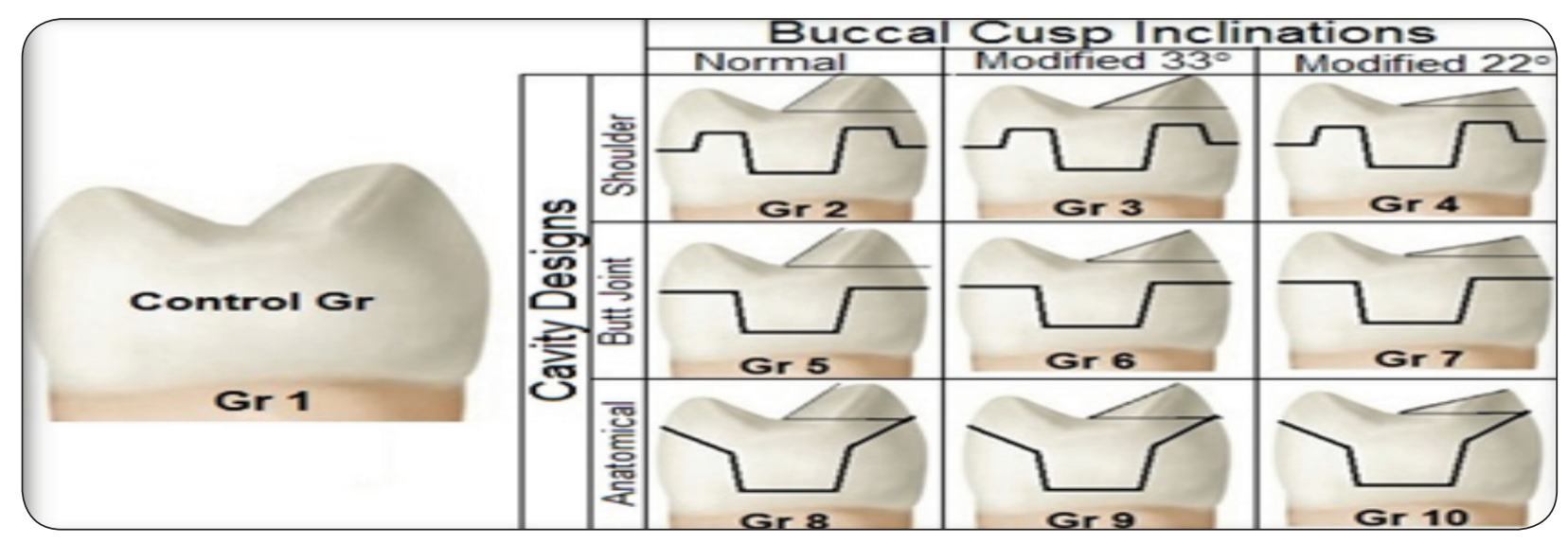

Fig. (1) Samples Grouping. 


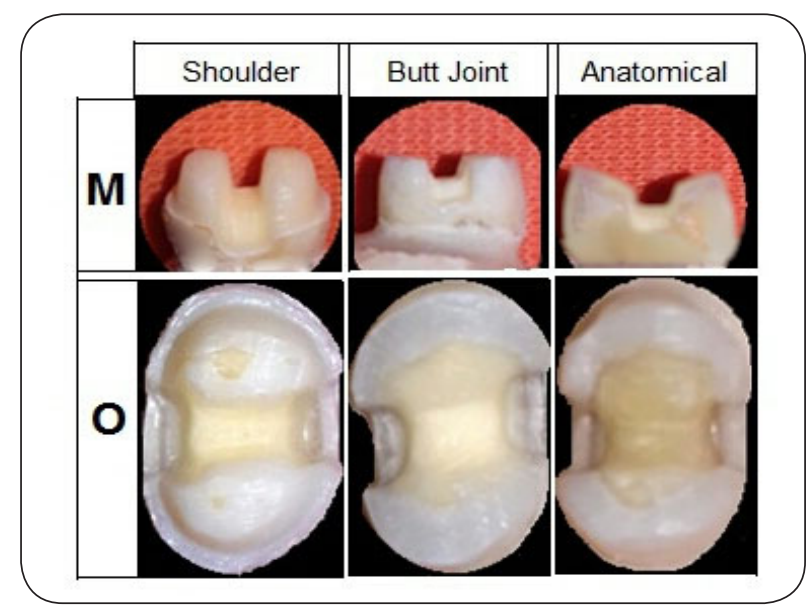

Fig. (2) Different cavity designs.

\section{Overlays construction;}

Overlays were constructed indirectly from Ceram.X SpherTec (Dentsply) using indices of three different buccal cusp inclinations. To standardize the final anatomy of the restorations, the following procedure was used;

1. Thirty silicon occlusal indices (Zetalabor; Zhermack SPA, Badia Polesine, RO, Italy) of a natural maxillary $1^{\text {st }}$ premolar were taken for fabrication of overlays with normal buccal cusp inclination ( Gr 2,5,8).

2. Then, the inclination of the buccal cusp was modified to be $33^{\circ}$ using tapered stone (Zhengzhou Smile Dent Equip, China) and thirty silicon indices were taken for fabrication of overlays with modified $33^{\circ}$ buccal cusp inclination $(\mathrm{Gr} 3,6,9)$.

3. The degree of cusp inclination was measured using VISTA scan Resetter (DURR DENTAL, Safwan, Germany) with software program (DBS WIN_5.7.1_Build_13164) and confirmed by a protractor overlapping the digitized image of the tooth, ${ }^{(22)}$ fig 3 .

4. Finally, the inclination of the buccal cusp was modified to be $22^{\circ}$ and thirty silicon indices were taken for fabrication of overlays with modified $22^{\circ}$ buccal cusp inclination ( $\left.\mathrm{Gr} 4,7,10\right)$.

5. The indices were filled with ceram.x Sphere TEC $^{\mathrm{TM}}$ (Dentsply), placed over the lubricated preparations and light cured (Led, Light Curing Unit, Germany) for forty seconds.

6. The blocks were separated from indices, trimmed, finished and polished with rubber cups and points (Identoflex; Kerr Corp).

7. The overlays were removed from the prepared teeth and ready for cementation. (Figs 4)

8. A bucco-palatally sectioned index and a caliper were used to standardize the thickness of the occlusal surfaces

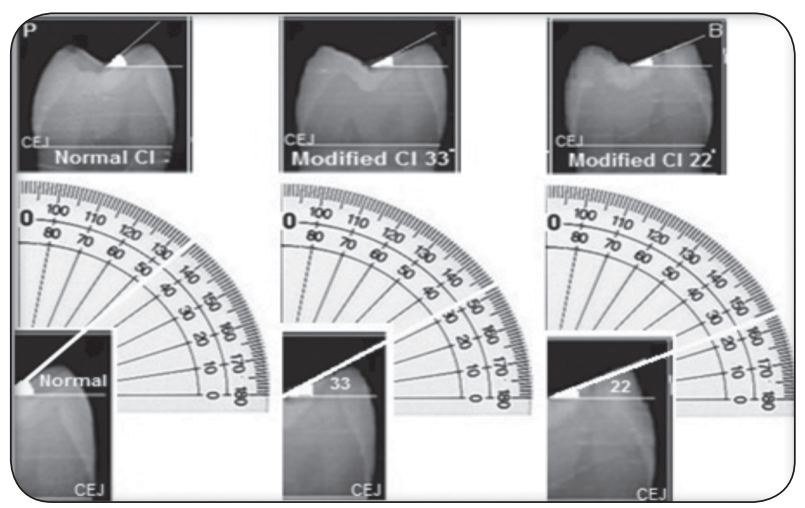

Fig. (3) Normal and modified buccal cusp inclinations.
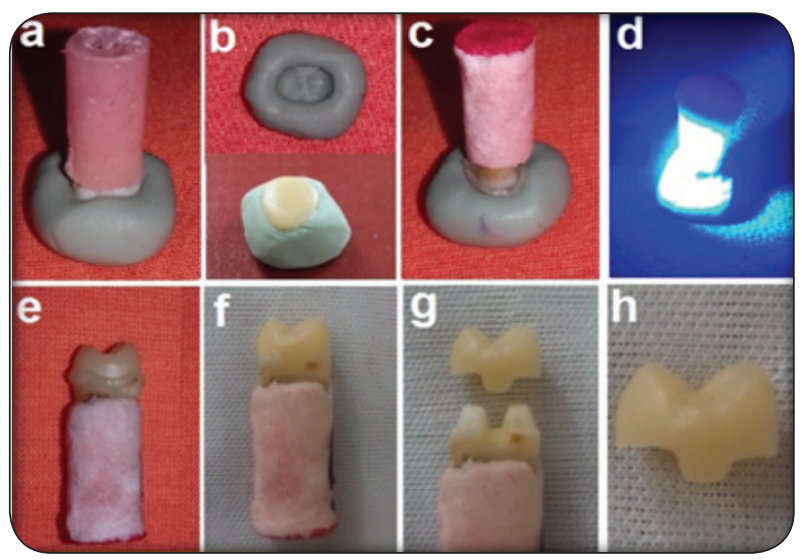

Fig. (4) Overlays Construction. 


\section{Overlays cementation;}

Samples were cemented using RelyX Ultimate resin cement after surface conditioning of the tooth structure and intaglio surfaces of the constructed overlays, in accordance with manufacturer instructions. Figs (5)

Surface treatment of tooth structure by etching for 15 seconds with Blue Etch $(36 \%$ phosphoric acid, StalowaWola, Polska) then rinsing, drying, and bonding (Single Bond, 3M, ESPE, Germany). Conditioning of the ceram.x SphereTec (Dentsply) intaglio surfaces by sandblasting with aluminium oxide according to manufacturer instructions then cleaned with distilled water in an ultrasonic unit (Bredent, Senden, Germany) for 1 minute and gently air dried. A layer of Single Bond adhesive (3M, ESPE, Germany) was applied using microbrush and allowed to react for 20 seconds.

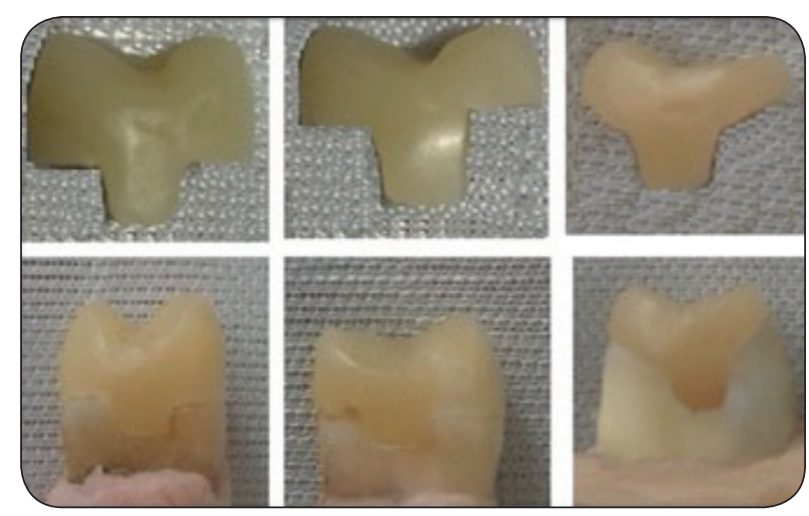

Fig. (5) Overlays Cementation (Proximal View)

After cementation, samples were stored for 24 hours in distilled water at $37^{\circ} \mathrm{C}$, then thermocycled in automatic thermal cycling machine (Ropota, automated thermo- cycling, Turkey) for 5000 cycles in water bath at 5 and $55^{\circ} \mathrm{C}$ with a dwell time of 30 seconds.

\section{Testing Procedures:}

All samples were individually mounted on a computer controlled mechanical testing machine (Model 3345; Instron Industrial Products, Norwood,MA, USA) with a loadcell of $5 \mathrm{kN}$ and data were recorded using computer software (Instron ${ }^{\circledR}$ Bluehill Lite Software). Samples were secured to the lower fixed compartment of testing machine by tightening screws. Fracture test was done by compressive mode of load applied occlusally using a metallic rod with round tip (3.8 $\mathrm{mm}$ diameter) attached to the upper movable compartment of testing machine traveling at cross-head speed of $1 \mathrm{~mm} / \mathrm{min}$ with $2 \mathrm{~mm}$ thick tin foil sheet in-between to achieve homogenous stress distribution and minimization of the transmission of local force peaks, ${ }^{(23)}$ fig (6). The load at failure manifested by an audible cracking sound and confirmed by a sharp drop at load-deflection curve recorded using computer software (Bluehill Lite Software Instron ${ }^{\circledR}$ Instruments). The load required to fracture was recorded in Newton.

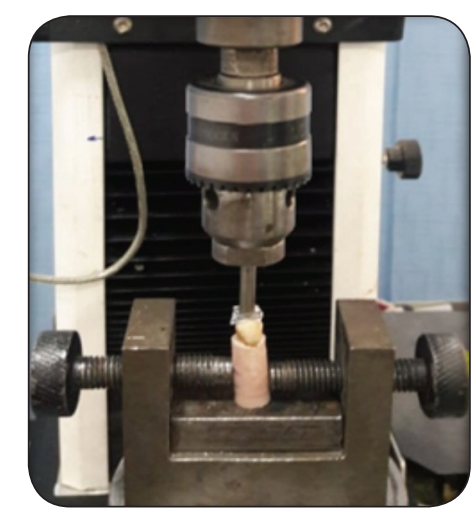

Fig. (6) Fracture resistance test in universal testing machine.

\section{Failure mode assessment}

The fractured samples were examined using a magnifying lens (10X, Optics Co, Ltd, China) to determine the fracture patterns according to location of the fracture, based on previous publications, ${ }^{(24,25)}$ as follows; type I; Restorable coronal fractures above the CEJ, and type II; Catastrophic vertical coronal/root fractures below the CEJ.

\section{Statistical analysis}

Statistical analysis was then performed using a commercially available software program (SPSS 18; SPSS, Chicago, IL, USA). Values were presented 
as mean and standard deviation (SD. Data was explored for normality using Kolmogorov-Smirnov test of normality). Obtained values were parametric and were compared between groups using one way analysis of variance (ANOVA) test, followed by Tukey's post hoc test when ANOVA revealed a significant difference. The level of significance was set at $\mathrm{P}<0.05$.

\section{RESULTS}

\section{I- Comparison of all groups}

The highest mean fracture load value was recorded in $\mathrm{CG}$, followed by $\mathrm{A} / 22^{\circ} \mathrm{CI}$, then $\mathrm{Sh} / 22^{\circ} \mathrm{CI}$ and $\mathrm{B} / 22^{\circ} \mathrm{CI}$, then $\mathrm{A} / 33^{\circ} \mathrm{CI}$ and $\mathrm{Sh} / 33^{\circ} \mathrm{CI}$, then $\mathrm{B} / 33^{\circ} \mathrm{CI}$ and $\mathrm{A} / \mathrm{NCI}$, then sh/NCI, with the least value recorded in $\mathrm{B} / \mathrm{NCI}$. ANOVA test revealed that the difference between groups was statistically significant $(\mathrm{p}=0.00)$. Tukey' s post hoc test revealed no significant difference between $\mathrm{Sh} / 33^{\circ} \mathrm{CI}$, $\mathrm{Sh} / 22^{\circ} \mathrm{CI}, \mathrm{B} / 33^{\circ} \mathrm{CI}, \mathrm{B} / 22^{\circ} \mathrm{CI}, \mathrm{A} / \mathrm{NCI}$ and $\mathrm{A} / 33^{\circ} \mathrm{CI}$. (Table 1, Fig 7)

Table (1): Comparison of fracture load $(N)$ in different groups and control (ANOVA test)

\begin{tabular}{|c|c|c|c|}
\hline Group/Subgroup & Mean & SD & $\mathbf{P}$ \\
\hline CG & $1114^{a}$ & 120.6 & \multirow{10}{*}{$0.00^{*}$} \\
\hline sh/N CI & $758.63^{\mathrm{d}}$ & 80.2 & \\
\hline $\mathrm{sh} / \mathbf{3 3}^{\circ} \mathrm{CI}$ & $880.467^{\circ}$ & 90.4 & \\
\hline $\mathrm{sh} / 22^{\circ} \mathrm{CI}$ & $994.3^{c}$ & 91.3 & \\
\hline $\mathrm{B} / \mathrm{N} \mathrm{CI}$ & $711.9^{\mathrm{e}}$ & 69.9 & \\
\hline $\mathrm{B} / \mathbf{3 3}^{\circ} \mathrm{CI}$ & $860^{\mathrm{c}}$ & 89.4 & \\
\hline $\mathrm{B} / 22^{\circ} \mathrm{CI}$ & $976.2^{\mathrm{c}}$ & 100.6 & \\
\hline $\mathbf{A} / \mathbf{N} \mathbf{C I}$ & $810.2^{\mathrm{c}}$ & 83.2 & \\
\hline $\mathbf{A} / \mathbf{3 3}^{\circ} \mathbf{C I}$ & $925.3^{\mathrm{c}}$ & 94.3 & \\
\hline $\mathrm{A} / 22^{\circ} \mathrm{CI}$ & $1032.3^{\mathrm{b}}$ & 105.2 & \\
\hline
\end{tabular}

Significance level $p<0.05$, *significant

Tukey's post hoc test: means sharing the same superscript letter are not significantly different

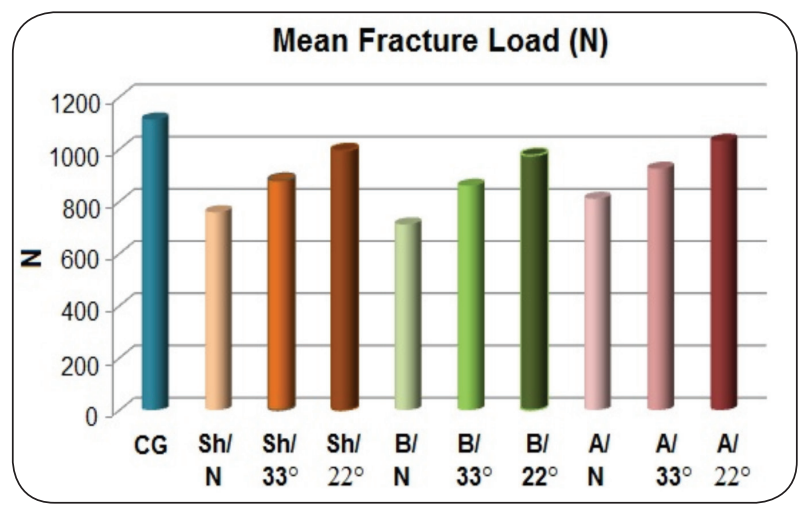

Fig. (7) Bar chart illustrating mean fracture load (N) in all groups

\section{II- Comparison according to cavity design;}

The highest mean fracture value was recorded in anatomical design, then shoulder design, with the least value in butt joint design. ANOVA test revealed that the differences were not statistically significant $(\mathrm{p}=0.28 \& \mathrm{p}=0.44)$, regarding $33^{\circ} \&$ $22^{\circ} \mathrm{CI}$, respectively. However, the difference was statistically significant in N CI groups $(\mathrm{p}=0.03)$. Tukey's post hoc test revealed no significant difference between shoulder and butt joint designs. (Table 2, Fig 8)

Table (2) Comparison of fracture load (N) in different groups (ANOVA test)

\begin{tabular}{|c|c|c|c|c|c|c|c|}
\hline \multirow{2}{*}{} & \multicolumn{2}{|c|}{$\begin{array}{c}\text { Shoulder } \\
\text { design (Sh) }\end{array}$} & \multicolumn{2}{c|}{$\begin{array}{c}\text { Butt joint } \\
\text { design (B) }\end{array}$} & \multicolumn{2}{c|}{$\begin{array}{c}\text { Anatomical } \\
\text { design (A) }\end{array}$} & \multirow{2}{*}{ P } \\
\cline { 2 - 7 } & Mean & SD & Mean & SD & Mean & SD & \\
\hline N CI & $758.633^{\mathrm{B}}$ & 80.2 & $711.9^{\mathrm{B}}$ & 69.9 & $810.2^{\mathrm{A}}$ & 83.2 & $0.03^{*}$ \\
\hline $\mathbf{3 3}^{\circ} \mathbf{C I}$ & 880.467 & 90.4 & 860 & 89.4 & 925.3 & 94.3 & $0.28^{\mathrm{ns}}$ \\
\hline $\mathbf{2 2}^{\circ} \mathbf{C I}$ & 994.3 & 91.3 & 976.2 & 100.6 & 1032.3 & 105.2 & $0.44^{\mathrm{ns}}$ \\
\hline
\end{tabular}

Significance level $p<0.05$, *significant, $n s=n o n$ significant

Tukey's post hoc test: means sharing the same superscript letter are not significantly different 


\section{III- Comparison according to cusp inclination;}

The highest mean value was recorded in $22^{\circ} \mathrm{CI}$, then $33^{\circ} \mathrm{CI}$, with the least value in N CI. ANOVA test revealed that the difference was statistically significant $(\mathrm{p}=0.00)$ in all designs. Tukey's post hoc test revealed a significant difference between each two cusp inclinations in shoulder and anatomical design groups. However, regarding butt joint design, there was no significant difference between $22^{\circ} \mathrm{CI} \& 33^{\circ} \mathrm{CI}$. (Table 3, Fig 8 )

Table (3) Comparison of fracture load $(N)$ in cusp inclination within the same group (ANOVA test)

\begin{tabular}{|c|c|c|c|c|c|c|}
\hline \multirow{2}{*}{} & \multicolumn{2}{|c|}{$\begin{array}{c}\text { Shoulder design } \\
\text { (Sh) }\end{array}$} & \multicolumn{2}{c|}{$\begin{array}{c}\text { Butt joint } \\
\text { design (B) }\end{array}$} & \multicolumn{2}{c|}{$\begin{array}{c}\text { Anatomical } \\
\text { design (A) }\end{array}$} \\
\cline { 2 - 7 } & Mean & SD & Mean & SD & Mean & SD \\
\hline N CI & $758.633^{\mathrm{c}}$ & 80.2 & $711.9^{\mathrm{b}}$ & 69.9 & $810.2^{\mathrm{c}}$ & 83.2 \\
\hline $\mathbf{3 3}^{\circ} \mathbf{C I}$ & $880.467^{\mathrm{b}}$ & 90.4 & $860^{\mathrm{a}}$ & 89.4 & $925.3^{\mathrm{b}}$ & 94.3 \\
\hline $\mathbf{2 2}^{\circ} \mathbf{C I}$ & $994.3^{\mathrm{a}}$ & 91.3 & $976.2^{\mathrm{a}}$ & 100.6 & $1032.3^{\mathrm{a}}$ & 105.2 \\
\hline $\mathbf{P}$ & \multicolumn{2}{|c|}{$0.00^{*}$} & \multicolumn{2}{|c|}{$0.00^{*}$} & \multicolumn{2}{c|}{$0.0001^{*}$} \\
\hline
\end{tabular}

Significance level $p<0.05$, *significant

Tukey's post hoc test: means sharing the same superscript letter are not significantly different

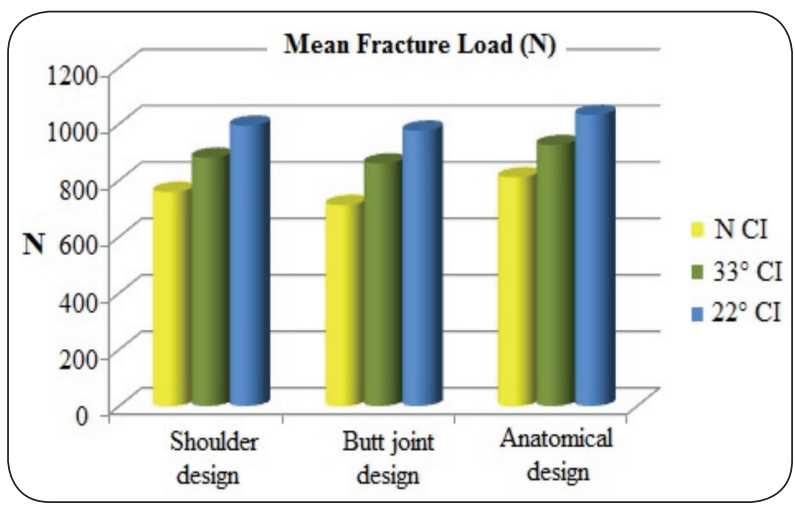

Fig. (8) Bar chart illustrating mean fracture load (N) in different cusp inclinations and cavity designs

\section{IV- Failure mode assessment}

The intact teeth predominantly fractured with restorable patterns. The most common failure pattern in shoulder design samples was Type I (Restorable). The highest restorable fracture rate $(90 \%)$ was observed in $\mathrm{Sh} / 22^{\circ} \mathrm{CI}$ overlays. Conversely, the most common failure pattern in anatomic and butt joint design samples was Type II (Catastrophic). (Table 4, Fig 9)

Table (4) Failure patterns and percentages of restorable failure in each group

\begin{tabular}{|c|c|c|c|c|}
\hline \multirow{2}{*}{$\begin{array}{l}\text { Cavity } \\
\text { design }\end{array}$} & \multirow{2}{*}{$\begin{array}{c}\text { Cusp } \\
\text { inclination }\end{array}$} & \multicolumn{2}{|c|}{ Failure Pattern } & \multirow{2}{*}{$\begin{array}{c}\text { Restorable } \\
\text { fracture } \\
(\%)\end{array}$} \\
\hline & & Type I & $\begin{array}{c}\text { Type } \\
\text { II }\end{array}$ & \\
\hline \multicolumn{2}{|c|}{ Control Group } & 8 & 2 & $80 \%$ \\
\hline \multirow{3}{*}{$\begin{array}{l}\text { Shoulder } \\
\text { design }\end{array}$} & N CI & 7 & 3 & $70 \%$ \\
\hline & $33^{\circ} \mathrm{CI}$ & 7 & 3 & $70 \%$ \\
\hline & $22^{\circ} \mathrm{CI}$ & 9 & 1 & $90 \%$ \\
\hline \multirow{3}{*}{$\begin{array}{l}\text { Butt Joint } \\
\text { design }\end{array}$} & N CI & 4 & 6 & $30 \%$ \\
\hline & $33^{\circ} \mathrm{CI}$ & 3 & 7 & $30 \%$ \\
\hline & $22^{\circ} \mathrm{CI}$ & 3 & 7 & $40 \%$ \\
\hline \multirow{3}{*}{$\begin{array}{l}\text { Anatomical } \\
\text { design }\end{array}$} & $\mathrm{N} \mathrm{CI}$ & 3 & 7 & $30 \%$ \\
\hline & $33^{\circ} \mathrm{CI}$ & 0 & 10 & $0 \%$ \\
\hline & $22^{\circ} \mathrm{CI}$ & 1 & 9 & $10 \%$ \\
\hline
\end{tabular}

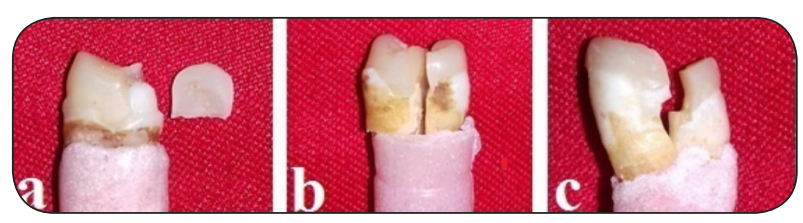

Fig. (9) The most common failure patterns; a) shoulder design showed $70-90 \%$ restorable fracture, b\&c) butt joint and anatomic design showed $60-70 \%$ and $70-100 \%$ catastrophic fracture, respectively.

\section{DISCUSSION}

The anatomy of maxillary premolars is susceptible to cusp deflection and fracture under excessive occlusal forces. ${ }^{(26)}$ It is necessary to protect cusps when the width of the cavity isthmus is greater than $2 / 3$ of the inter-cuspal distance or $1 / 2$ of the bucco-lingual distance. ${ }^{(17)}$ Therefore, this study 
was conducted to evaluate the fracture resistance of maxillary $1^{\text {st }}$ premolar overlays with different preparations at different cuspal inclinations.

According to manufacturer, ceram.x Sphere TEC $^{\mathrm{TM}}$ a nano-hybrid universal composite is the ideal for durable stress bearing posterior restorations. Being less expensive than ceramics, selection of ceram.x Sphere TEC was simply based on the fact that the use of bonded cuspal coverage composite restorations support the remaining tooth structure, prevent additional tissue loss and exhibit more homogeneous distributions of occlusal forces. ${ }^{(17,27-}$ ${ }^{30)}$ Consequently, ceram.x supports the conservative approach in terms of function and esthetics. In this study, ceram.x Sphere TEC overlays were cemented with RelyX Ultimate resin cement, as etching and adhesive techniques are known to reinforce the dental structure and enhance resistance to fracture. $(17,31)$

The results of the present study revealed that both cavity design and cusp inclination affect fracture resistance, thus the null hypothesis tested was rejected.

In this study, control group showed fracture resistance of $1114 \mathrm{~N}$ that almost coincided with previous studies. ${ }^{(32-35)}$ The fracture resistance values recorded in this study ranged from 758 to $1032 \mathrm{~N}$. In clinical literature, it was reported the normal force at the premolar region varies from 222 to $445 \mathrm{~N},{ }^{(36)}$ but from 520 to $800 \mathrm{~N}^{(36)}$ during clenching. Therefore, these results are within the clinically accepted limit.

Regarding cusp inclination, by reducing the degree of inclination to $22^{\circ}$, fracture resistance increased. This was directly attributed to better stress distribution. ${ }^{(22,37)}$ When vertical loads are applied on occlusal surfaces with a steeper cusp inclination, increased lateral forces are produced result in decreasing fracture load. Therefore, decreasing cusp inclination is considered one of strategies of reducing lateral forces in implant-supported crowns. ${ }^{(22)}$ These findings are consistent with
Antenucci et $\mathrm{al}^{(37)}$ study, in which the stresses on the tooth/restoration interface decreased with decreasing cusp inclination. Similar results found by Rocha et $\mathrm{al}^{(22)}$ who confirmed that the crowns with reduced cusp inclination exhibited significantly higher fracture load than those with standard cusp inclination.

On natural maxillary premolars, the relation between different cusp inclination and maximum resistance was studied and concluded that the resistance increases as cusp inclination decreases. ${ }^{(20)}$ According to Liu et al, ${ }^{(38)}$ modifying the occlusal design has many advantages to improve the mechanical stability and long-term success of restorations of maxillary premolars with large amount- dentin loss. First, it is important to decrease oblique forces by reducing the lateral occlusal contact area and by preventing contact on the top of buccal cusp, hence protecting the remaining dentin from fracture. Second, in case of maxillary premolars with palatal dentin loss (i.e. when teeth have defect where the load is applied), two options suggested to avoid the risk of overloading; reducing the buccal cusp inclination or keeping occlusal contact at the bottom of a high cusp where oblique load to be applied. ${ }^{(38)}$

Regarding cavity design, the anatomical ${ }^{(24)}$ or sometimes called concave ${ }^{(25)}$ design showed the highest fracture resistance followed by cusp shoulder design, while the least resistance recorded by butt joint (horizontal or flat) ${ }^{(24,25)}$ design. This is most likely due to the axial direction of the cusp reduction design, which would lead to a favorable distribution of occlusal forces that perpendicularly transfer to the occlusal surface when a compressive load is applied.(24) Consequently, less forces analysis occurs. Furthermore, the anatomical design maintains the most occlusal thickness in the center of the restorations.

Moreover, although the anatomic design is more wedge-shaped than the flat and the shoulder designs, it recorded the highest resistance. It might be attributable to the improved resistance to fracture 
related to the selected restorative material and cusp inclination, as well. The mechanical properties of the materials selected to restore a tooth can influence the behavior of stress distribution at the tooth/restoration interface. ${ }^{(36)}$ It was reported that composites have a $57 \%$ greater ability to absorb impacts than ceramics. ${ }^{(39)}$ With overlay restorations, favorable cusp inclinations guarantees better resistance to fracture. ${ }^{(40-43)}$

This is agreed to Kalay et al ${ }^{(24)}$ who compared the anatomic overlay design at three different occlusal thicknesses $(1.5,2.5$ and $3.5 \mathrm{~mm})$ to the butt-joint design. The anatomic design recorded higher fracture resistances than butt-joint design at all occlusal thicknesses. On contrary, these findings are inconsistent to Al Khalifah ${ }^{(25)}$ study, in which the different overlay preparations had no effect on fracture resistance. This difference could be explained by the different restorative materials used to construct overlays on molars, not premolars as in the current study.

Comparing to butt joint design, the higher fracture resistance recorded by shoulder design samples was attributed to the shoulder margin that seemed to have the effect of ferrule which resulted in better stress distribution. ${ }^{(44,45)}$ In addition, the shoulder design overwrapped or capped the cusps, thus enhanced resistance to fracture. This agreed with Oyar and Durkan ${ }^{(45)}$ who concluded that cavity designs with shoulder margins showed the highest fracture resistance, while butt joint designs had the lowest fracture resistance. On the other hand, cusp capping entails removal of enamel on the outer cusp slopes. Also, having a thin circumferential restoration margin might increase the risk of restoration chipping. That is why $70-90 \%$ restorable fracture occurred.

In addition to simplicity, the flat design preserved the outer cuspal slopes and maintained increased restoration thickness at the margins, possibly decreasing chipping and increasing the incidence of catastrophic failure.
The most common mode of failure was catastrophic $(70-100 \%)$ in the anatomic design groups because this design produced more wedgeshaped restoration resulted in a higher frequency of catastrophic fracture extending below the CEJ than the butt joint. As satisfactory alternative design of $90 \%$ restorable fracture rate exists (i.e. cusp shoulder design), there is no reason to use the anatomic design. ${ }^{(25)}$

The limitation of this study is that no mechanical loading was applied as part of artificial aging process. Future work should determine the interaction between different overlay designs and material type including glass ceramic and zirconia and their impact on failure pattern.

\section{CONCLUSIONS}

Within the limitations of this study, the following could be concluded;

1) Cusp shoulder and butt joint designs have comparable fracture resistances, but extremely different effect on failure pattern. 2) The teeth restored with cusp shoulder designs exhibited the highest percentages of restorable fractures (7090\%). 3) Anatomical design presents the highest fracture resistance. However, 70-100\% catastrophic failure is suspected. 4) Fracture resistance increases significantly by decreasing cusp inclination of overlay restorations.

\section{REFERENCES}

1. Macpherson LC and Smith BGN. Replacement of missing cusps: an in vitro study. J Dent. 1994; 22: 118-20.

2. Bader JD, Martin JA, Shugars DA. Incidence rates for complete cusp fracture. Community Dent Oral Epidemiol. 2001; 29(5):346-53.

3. Cubas GBA, Habekost L, Camacho GB, Cenci TP. Fracture resistance of premolars restored with inlay and onlay ceramic restorations and luted with two different agents. Journal of Prosthodontic Research. 2011;55: 53-9. 
4. Angambakkam RP and Arunajatesan S. Cracks and fractures in teeth: Review Article. J of Oper Dent and Endodontics. 2017; 2(1): 25-30.

5. Kuo WCH and Chang YH. Tooth-colored onlay restorations of cusp-fractured maxillary premolars-cases report. J Dent Sci. 2008; 3(1):49-56.

6. Dawson PE. Functional occlusion: from TMJ to smile design. St. Louis: Mosby; 2006. p. 105.

7. Naumann M, Preuss A, Rosentritt M. Effect of incomplete crown ferrules on load capacity of endodontically treated maxillary incisors restored with fiber posts, composite buildups, and all-ceramic crowns: an in vitro evaluation after chewing simulation. Acta Odontol Scand.2006;64:31-6.

8. Ng CC, Dumbrigue HB, Al-Bayat MI, Griggs JA, Wakefield CW. Influence of remaining coronal tooth structure location on the fracture resistance of restored endodontically treated anterior teeth. J Prosthet Dent. 2006; 95:290-6.

9. Ferrari M,Cagdiaco MC,Grandini S, De Sanctis M, Goracci C. Post placement affects survival of endodontically treated premolars. J Dent Res. 2007; 86:729-34.

10. Schmitter M, Rammelsberg P, Lenz J, Scheuber S. Teeth restored using fiber reinforced posts: in vitro fracture tests and finite element analysis. Acta Biomater. 2010; 6:3747-54.

11. Mangold JT and Kern M. Influence of glass-fiber posts on the fracture resistance and failure pattern of endodontically treated premolars with varying substance loss: an in vitro study. J Prosthet Dent. 2011; 105:387-93.

12. Torbjorner A and Fransson B. A literature review on the prosthetic treatment of structurally compromised teeth. Int J Prosthodont. 2004; 17:369-76.

13. Jotkowitz A and Samet N. Rethinking ferrule: a new approach to an old dilemma. Br Dent J. 2010; 209:25-33.

14. Saridag S, Sevimay M, Pekkan G. Fracture Resistance of Teeth Restored with All-ceramic Inlays and Onlays: An in Vitro Study. Operative Dentistry J. 2013; 38(6): 626-34.

15. Opdam N, Frankenberger R, Magne P. From 'Direct Versus Indirect' Toward an Integrated Restorative Concept in the Posterior Dentition. Oper Dent. 2016; 41(S7):S27-S34.

16. Sevimli G, Cengiz S, Oruc MS. Endocrowns: Review Article. J Istanbul Univ Fac Dent 2015;49(2):57-63.

17. Morimoto S, Vieira GF, Agra CM, Sesma N, Gil C. Fracture Strength of Teeth Restored with Ceramic Inlays and Overlays. Braz Dent J. 2009; 20(2): 143-8.
18. Panahandeh $\mathrm{N}$ and Johar N. Effect of Different Cusp Coverage Patterns on Fracture Resistance of Maxillary Premolar Teeth in MOD Composite Restorations. Journal of Islamic Dental Association of IRAN. 2014; 25 (4): 22832.

19. Harsha MS, Praffulla M, Babu MR, Leneena G, Krishna TS, Divya G. The Effect of Cavity Design on Fracture Resistance and Failure Pattern in Monolithic Zirconia Partial Coverage Restorations - An In vitro Study. Journal of Clinical and Diagnostic Research. 2017; 11(5): ZC45-8.

20. Xie N, Liu Z, Wu C, Wang P, Song G, Zhi Chen Z. In vitro study on the impact of different cusp inclinations on cracked teeth. Biomed Res 2018; S205-8.

21. Rocca GT, Rizcalla N, Krejci I, Dietschi D. Evidencebased concepts and procedures for bonded inlays and onlays. Part II. Guidelines for cavity preparation and restoration fabrication. Int J Esthet Dent 2015;10(3):1-23.

22. Rocha COM, Longhini D, Pereira RP, Filho JNA. Influence of Cusp Inclination and Type of Retention on Fracture Load of Implant-Supported Crowns. Braz Dent J 2017; 28(1): 92-6.

23. Schultheis S, Strub JR, Gerds TA, Guess PC. Monolithic and bi-layer CAD/CAM lithium-disilicate versus metalceramic fixed dental prostheses: Comparison of fracture loads and failure modes after fatigue. Clin Oral Invest 2013;17:1407-13.

24. Kalay TS, Yildirim T, Ulker M. Effects of different cusp coverage restorations on the fracture resistance of endodontically treated maxillary premolars. J Prosthet Dent 2016; $1-7$.

25. Al Khalifah SAM. The Influence of Material Type, Preparation Design and Tooth Substrate on Fracture Resistance of Molar Onlays. UCLA Electronic Theses and Dissertations 2016; 12-41.

26. Soares PV, Santos-Filho PC, Martins LR, Soares CJ. Influence of restorative technique on the biomechanical behavior of endodontically treated maxillary premolars. Part I: fracture resistance and fracture mode. J Prosthet Dent 2008;99:30-7.

27. Rocca GT, Krejci I. Crown and post-free adhesive restorations for endodontically treated posterior teeth: from direct composite to endocrowns. Eur J Esthet Dent 2013;8: 156-79.

28. Magne P, Knezevic A. Thickness of CAD-CAM composite resin overlays influences fatigue resistance of endodontically treated premolars. Dent Mater 2009;25:1264-8. 
29. Mondelli RF, Ishikiriama SK, de Oliveira Filho O, Mondelli J. Fracture resistance of weakened teeth restored with condensable resin with and without cusp coverage. J Appl Oral Sci 2009;17:161-5.

30. Krifka S, Stangl M, Wiesbauer S, Hiller KA, Schmalz G. Influence of different cusp coverage methods for the extension of ceramic inlays on marginal integrity and enamel crack formation in vitro. Clin Oral Investig 2009;13:333-41.

31. Carvalho R, Martins M, Queiroz J. Influence of silane heat treatment on bond strength of resin cement to a feldspathic ceramic. Dent Mater J 2011;30(3):392-7.

32. Shafiei F, Memarpour M, Karimi F. Fracture resistance of cuspal coverage of endodontically treated maxillary premolars with combined composite-amalgam compared to other techniques. Oper Dent J 2011;36(4):439-447.

33. Xie KX, Wang XY, Gao XJ, Yuan CY, Li JX, Chu CH. Fracture resistance of root filled premolar teeth restored with direct composite resin with or without cusp coverage," Int Endodont J 2012;45(6):524-9.

34. Joshi C, Patel M, Desai P, Patel P. Comparative analysis of fracture resistance of maxillary premolars with class II MOD cavities restored with novel nanocomposites including fiber reinforced composite restorative system: a step ahead in composite dentistry. Advances in Human Biology J 2014;4(2):14-21.

35. Atiyah AH and Baban LM. Fracture resistance of endodontically treated premolars with extensive MOD cavities restored with different composite restorations: an in vitro Study. Journal of Baghdad College of Dentistry 2014;26(1):7-15.

36. Tavarez RRJ, Firoozmand LM, Silva MB, Malheiros AS, Bandéca MC. Overlays or Ceramic Fragments for Tooth Restoration: An Analysis of Fracture Resistance. J Contemp Dent Pract 2014;15(1):56-60.

37. Antenucci RMF, Pellizzer EP, Carvalho PSP, Goiato
MC, Noritomi PY. Influence of Cusp Inclination on Stress Distribution in Implant-Supported Prostheses. A 3Dimensional Finite Element Analysis. J Prosthodont 2010; 19: 381-6.

38. Liu S, Liu Y, Xu J, Rong Q, Pan S. Influence of occlusal contact and cusp inclination on the biomechanical character of a maxillary premolar: A finite element analysis. J Prosthet Dent 2014;1-8

39. Magne P, Belser UR. Porcelain versus composite inlays/ onlays: effects of mechanical loads on stress distribution, adhesion, and crown flexure. Int J Periodontics Restorative Dent 2003;23:543- 55 .

40. Ibrahim AM, Richards LC, Berekally TL. Effect of remaining tooth structure on the fracture resistance of endodontically-treated maxillary premolars: an in vitro study. J Prosthet Dent 2016;115:290-5.

41. Ng CC, Dumbrigue HB, Al-Bayat MI, Griggs JA, Wakefield CW. Influence of remaining coronal tooth structure location on the fracture resistance of restored endodontically treated anterior teeth. J Prosthet Dent 2006;95:290-6.

42. Liu S, Liu Y, Xu J, Rong Q, Pan S. Influence of occlusal contact and cusp inclination on the biomechanical character of a maxillary premolar: a finite element analysis. J Prosthet Dent 2014;112:1238-45.

43. Silva GR, Silva NR, Soares PV, Costa AR, FernandesNeto AJ, Soares CJ. Influence of different load application devices on fracture resistance of restored premolars. Braz Dent J 2012;23:484-9.

44. Schmidlin PR, Stawarczy B, DeAbreu D, Bindl A, Ender A. Fracture resistance of endodontically treated teeth without ferrule using a novel $\mathrm{H}$-shaped short post. Quintessence Int 2015; 46: 2.

45. Oyar P and Durkan R. Effect of Cavity Design on the Fracture Resistance of Zirconia Onlay Ceramics. Niger J Clin Pract 2018; 21(6):687-91. 


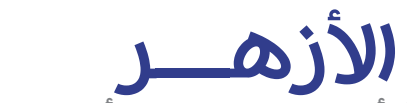 \\ مجلة أسيوط لطب الأسنان
}

النشر الرسمي لكلية طب الأسنان جامعة الأزهر أسيوط لكاطية

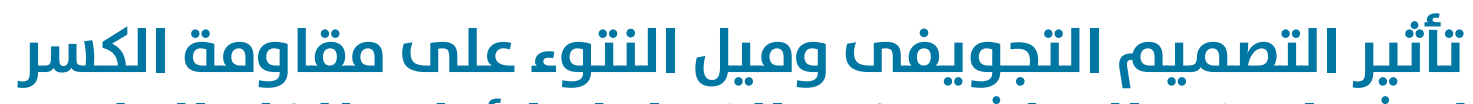 للحشوات غير المباشرة في التجويفي الضواحك الأوله للفكلك العلوي: دراسة في المختبر}

رقية محمد العصار1* ، أميرة محمد سامى2 ، رانيا عادل أمين1

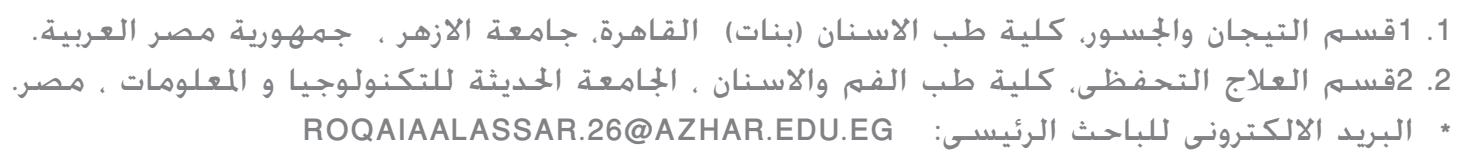

(الملخص:

الهـدف: تهدف هذه الدراسـة المعملية الى معرفة تأثير التصميم التجـويفى وميل النتوء على مقاومة الكسر للحشـوات غير المباشـرة في الضواحك الاولى العلوية.

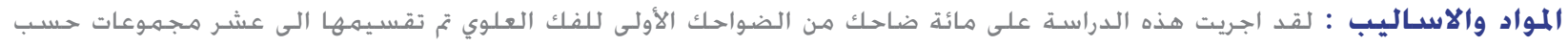

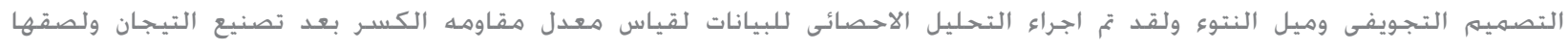
النتائج: ولقد اشارت النتائج الاحصائيه الى وجود فروق إحصائية بين الجمموعات علما انه لا يوجد فروق احصائيه بين الجمموعات الغُضرة بزوايا 22و33

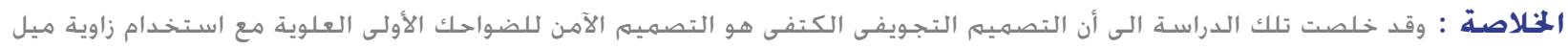

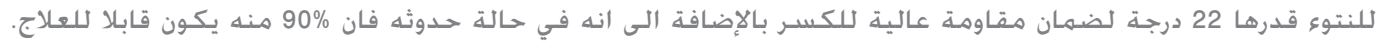
الكلمات المفتاحية: التصميم التجويفى، ميل النتوء ،مقاومه الكسـر، حشوه غير مباشره, التركيبات ، الضواحك 